\title{
Total Tumor mRNA-pulsed Tumor-specific Ex vivo-expanded Autologous Lymphocyte Transfer Cells
}

National Cancer Institute

\section{Source}

National Cancer Institute. Total Tumor mRNA-pulsed Tumor-specific Ex vivo-expanded

Autologous Lymphocyte Transfer Cells. NCI Thesaurus. Code C155969.

A preparation of ex vivo expanded, autologous lymphocyte transfer cells (XALTs) that are loaded with total tumor RNA (TTRNA) derived from autologous tumor cells, with potential immunostimulatory and antineoplastic activities. Upon re-infusion of the TTRNA-loaded ALTs into the patient, these ALTs may elicit a highly specific cytotoxic Tlymphocyte $(\mathrm{CTL})$ response against the tumor-associated antigens (TAAs) encoded by the TTRNA. 